\title{
Microscopic polyangiitis presenting with bilateral spontaneous perinephric haematoma
}

\author{
Dhilip Andrew 지 , Karthik Shyam ㄷ , Jovis Johny
}

Radiology, St John's Medical College Hospital, Bangalore, Karnataka, India

Correspondence to Dr Karthik Shyam;

dr.karthikshyam@gmail.com

Accepted 30 September 2020

Check for updates

(C) BMJ Publishing Group Limited 2020. No commercial re-use. See rights and permissions. Published by BMJ.

\begin{tabular}{l}
\hline To cite: Andrew D, \\
Shyam K, Johny J. BMJ Case \\
Rep 2020;13:e239282. \\
doi:10.1136/bcr-2020- \\
239282 \\
\hline
\end{tabular}

\section{DESCRIPTION}

A 50-year-old female patient presented to the emergency room with intermittent fever and bilateral upper/lower limb weakness for 2 weeks and intermittent abdominal pain for 1 week. On general examination there were features of hypotension, tachypnoea and pallor. On nervous system examination there was bilateral foot drop, with decreased power of 3 out of 5 in bilateral upper/lower limbs with absent deep tendon reflex. On respiratory examination there was crepitation in bilateral lower lobes. The rest of the systemic examination was unremarkable.

Routine blood investigations revealed haemoglobin of $50 \mathrm{~g} / \mathrm{L}$, creatinine of $1.9 \mathrm{mg} / \mathrm{dL}$, total count of $21.93 \times 10^{9} / \mathrm{L}$ and erythrocyte sedimentation rate of $150 \mathrm{~mm} /$ hour. Due to low haemoglobin and hypotension, the patient underwent plain CT of the abdomen, which revealed left perinephric haematoma (figure 1A). After 48 hours the patient underwent contrast-enhanced CT of the abdomen, which revealed bilateral perinephric haematoma compressing the kidneys and multiple aneurysms of the branch vessels of bilateral renal arteries and hepatic artery (figure 1B-F). The patient developed haemoptysis on day 15 of admission. High-resolution CT of the chest revealed alveolar haemorrhage (figure $2 \mathrm{~A}, \mathrm{~B}$ ). Based on the imaging features, the possibility of a vasculitic cause was raised. Nerve biopsy showed features of vasculitis of medium-sized vessels and axonopathy. The patient had elevated levels of MPO ANCA (Myeloperoxidase Anti-Neutrophil Cytoplasmic Antibody). A final diagnosis of microscopic polyangiitis (MPA) was made based on imaging and laboratory parameters. The patient underwent bilateral percutaneous drainage of haematoma and was initiated on methylprednisolone and cyclophosphamide.

MPA is a rare vasculitis of small-sized vessels with or without involvement of medium-sized vessels and has predilection for capillaries, venules and arterioles. ${ }^{12}$ The incidence of MPA ranges between 1 and 9.4 per 100000 individuals per year and is the most common ANCA-associated vasculitis. ${ }^{34} \mathrm{MPA}$ most commonly presents with renal involvement (90\%), followed by pulmonary involvement $(22 \%) .^{5}$ The most common renal manifestation is Pauci-immunetype, rapidly progressive glomerulonephritis, while alveolar haemorrhage due to alveolar capillaritis is a common pulmonary manifestation. ${ }^{5}{ }^{6}$ Involvement of medium-sized renal vessels causing formation of microaneurysm and haemorrhage is more common in Polyarteritis Nodosa (PAN). ${ }^{7}$ Hence spontaneous perinephric haematoma formation in patients with

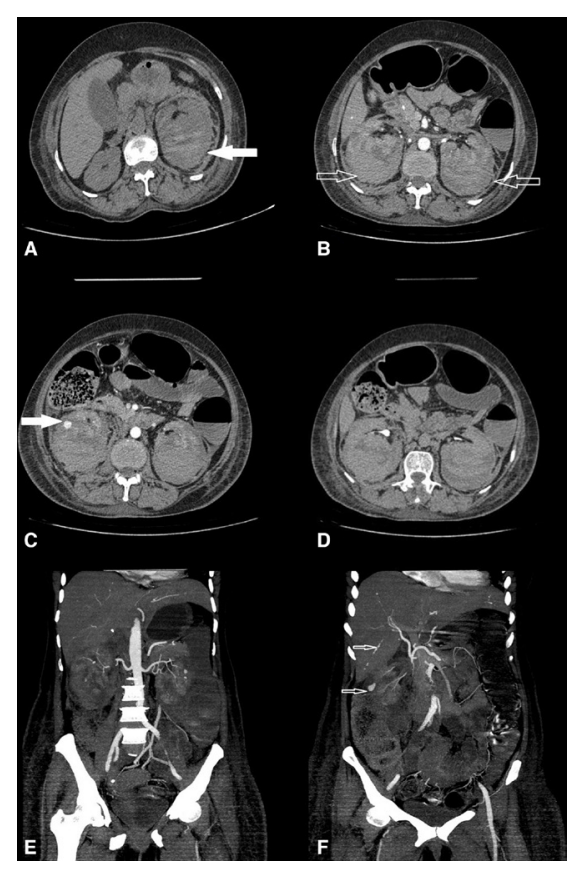

Figure 1 (A) Axial section of plain CT of the abdomen done on admission demonstrates left perinephric haematoma (white arrow). (B) Axial section of postcontrast $\mathrm{CT}$ after 48 hours demonstrates bilateral perinephric haematoma (arrows). (C) Axial postcontrast $\mathrm{CT}$ on arterial phase demonstrates microaneurysm in the right kidney (white arrow). (D) Delayed image demonstrates no significant change in the density of bilateral perinephric haematoma. (E and F) Coronal Maximum Intensity Projection (MIP) images demonstrate multiple microaneurysms in the liver and bilateral kidneys (arrows).

PAN is not uncommon, but rare in patients with MPA. ${ }^{8}$

According to Zhang et $a l^{9}$ the most common cause of renal haematoma is neoplasm (61\%),

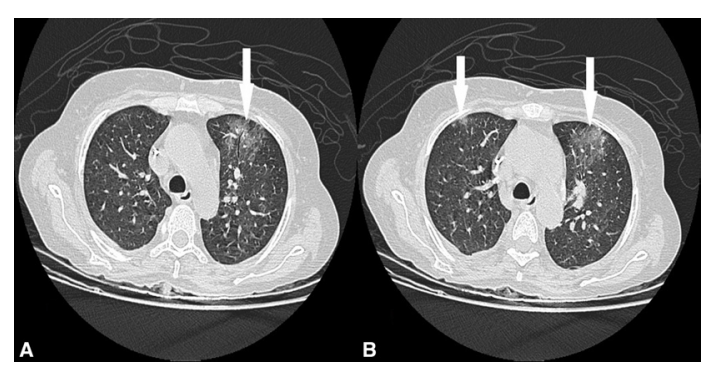

Figure 2 ( $A$ and $B$ ) Axial section of high-resolution $\mathrm{CT}$ of the chest demonstrates few foci of ground glass opacities in bilateral upper lobes (white arrows). 
followed by vascular cause (17\%). Among vascular causes, PAN is the most common. All patients with bilateral perinephric haematoma had PAN. Other causes of spontaneous perinephric haematoma are renal vein thrombosis, polycystic kidney disease and haemodialysis. Spontaneous haemorrhage due to anticoagulation therapy can occur in patients on haemodialysis. ${ }^{910}$

Pulmonary involvement is commonly seen in MPA and can present as fleeting focal infiltrates to massive lung haemorrhage. ${ }^{1}$ According to Ando et al $^{11}$ the most common chest CT findings in patients with MPA are ground glass opacities (94\%), consolidation $(78 \%)$, thickening of bronchovascular bundle $(51 \%)$ and honeycombing (37\%). Occasionally patients with MPA with chronic alveolar haemorrhage may experience pulmonary fibrosis and obstructive bronchitis. ${ }^{5}$ Contrast-enhanced CT can help differentiate the various causes of perinephric haematoma, while angiography can be used to evaluate vascular causes. However, to differentiate between PAN and MPA, biopsy and serum markers are required.

\section{Learning points}

- Spontaneous perinephric haematomas are commonly seen in PAN.

- Microscopic polyangiitis (MPA) can present with renal and pulmonary involvement; Rapidly Progressive Glomerulonephritis (RPGN) and alveolar haemorrhage are common renal and pulmonary manifestations.

- Common CT chest findings in patients with MPA are ground glass opacities, consolidation, thickening of bronchovascular bundle and honeycombing.

Contributors $\mathrm{DA}, \mathrm{KS}$, JJ contributed equally towards procuring and interpreting the images and clinical follow-up of the patient. DA was responsible for drafting the manuscript, and $\mathrm{KS}$ and JJ were responsible for editing and finalising the article.
Funding The authors have not declared a specific grant for this research from any funding agency in the public, commercial or not-for-profit sectors.

Competing interests None declared.

Patient consent for publication Obtained.

Provenance and peer review Not commissioned; externally peer reviewed.

\section{ORCID iDs}

Dhilip Andrew http://orcid.org/0000-0002-6154-3063

Karthik Shyam http://orcid.org/0000-0003-0998-9604

\section{REFERENCES}

1 Jennette JC, Falk RJ, Andrassy K, et al. Nomenclature of systemic vasculitides. Arthritis Rheum 1994;37:187-92.

2 Tamei N, Sugiura H, Takei T, et al. Ruptured arterial aneurysm of the kidney in a patient with microscopic polyangiitis. Intern Med 2008;47:521-6.

3 Mohammad AJ, Jacobsson LTH, Mahr AD, et al. Prevalence of Wegener's granulomatosis, microscopic polyangiitis, polyarteritis nodosa and Churg-Strauss syndrome within a defined population in southern Sweden. Rheumatology 2007:46:1329-37

4 Jennette JC, Thomas DB, Falk RJ. Microscopic polyangiitis (microscopic polyarteritis). Semin Diagn Pathol 2001;18:3-13.

5 Collins CE, Quismorio FP. Pulmonary involvement in microscopic polyangiitis. Curr Opin Pulm Med 2005;11:447-51.

6 Syed R, Rehman A, Valecha G, et al. Pauci-Immune crescentic glomerulonephritis: an ANCA-associated vasculitis. Biomed Res Int 2015;2015:e402826

7 Ishiwatari A, Endo M, Wakai S. Ruptured renal artery in microscopic polyangiitis: a case report and literature review. CEN Case Rep 2018;7:301-6.

8 Nakashima Y, Ohura M, Mima T, et al. Successful non-surgical treatment on bilateral spontaneous perirenal giant hematomas in rapidly progressive glomerulonephritis with MPO-ANCA positive. Ren Replace Ther 2015;1.

9 Zhang JQ, Fielding JR, Zou KH. Etiology of spontaneous perirenal hemorrhage: a meta-analysis. J Urol 2002;167:1593-6.

10 Malek-Marín T, Arenas D, Gil T, et al. Spontaneous retroperitoneal hemorrhage in dialysis: a presentation of 5 cases and review of the literature. Clin Nephrol 2010;74:229-44

11 Ando Y, Okada F, Matsumoto S, et al. Thoracic manifestation of myeloperoxidaseantineutrophil cytoplasmic antibody (MPO-ANCA)-related disease. CT findings in 51 patients. J Comput Assist Tomogr 2004;28:710-6.

Copyright 2020 BMJ Publishing Group. All rights reserved. For permission to reuse any of this content visit

https://www.bmj.com/company/products-services/rights-and-licensing/permissions/

BMJ Case Report Fellows may re-use this article for personal use and teaching without any further permission.

Become a Fellow of BMJ Case Reports today and you can:

- Submit as many cases as you like

- Enjoy fast sympathetic peer review and rapid publication of accepted articles

- Access all the published articles

Re-use any of the published material for personal use and teaching without further permission

Customer Service

If you have any further queries about your subscription, please contact our customer services team on +44 (0) 2071111105 or via email at support@bmj.com.

Visit casereports.bmj.com for more articles like this and to become a Fellow 